\title{
Case-control study of hospital admission with asthma in children aged 5-14 years: relation with road traffic in north west London
}

\author{
P Wilkinson, P Elliott, C Grundy, G Shaddick, B Thakrar, P Walls, S Falconer
}

Environmental Epidemiology Unit, Department of Public Health and Policy, London School of Hygiene and Tropical Medicine, London

WC1E 7HT, UK

$P$ Wilkinson

C Grundy

B Thakrar

P Walls

Department of

Epidemiology and

Public Health,

Imperial College

School of Medicine, St

Mary's Campus,

London W2 1PG, UK

P Elliott

G Shaddick

$S$ Falconer

Correspondence to: Professor P Elliott

Received 23 July 1996 Returned to author 15 October 1996 Revised manuscript received 19 August 1999

Accepted for publication

6 September 1999

\begin{abstract}
Background-Evidence for an association between road traffic pollution and asthma is inconclusive. We report a case-control study of hospital admissions for asthma and respiratory illness among children aged 5-14 in relation to proxy markers of traffic related pollution.

Methods-The study was based on routine hospital admissions data in 1992/3 and 1993/4 for North Thames (West) health region within the M25 motorway. Cases were defined as emergency admissions for asthma $(n=1380)$ or all respiratory illness including asthma $(n=2131)$, and controls $(n=5703)$ were other emergency admissions excluding accidents. Cases and controls were compared with respect to distance of residence from nearest main road or roads with peak hour traffic $>1000$ vehicles and traffic volume within $150 \mathrm{~m}$ of residence, obtained by Geographical Information System techniques. Statistical analysis included adjustment for age, sex, admitting hospital, and a deprivation score for the census enumeration district of residence.

Results-Adjusted odds ratios of hospital admission for asthma and respiratory illness for children living within $150 \mathrm{~m}$ of a main road compared with those living further away were, respectively, $0.93(95 \%$ CI 0.82 to 1.06$)$ and $1.02(95 \%$ CI 0.92 to 1.14).

Conclusions-This study showed no association between risk of hospital admission for asthma or respiratory illness among children aged 5-14 and proxy markers of road traffic pollution.

(Thorax 1999;54:1070-1074)
\end{abstract}

Keywords: childhood asthma; road traffic pollution

A number of studies have reported on the association between asthma or wheeze symptoms and road traffic. Positive findings have been reported between traffic volume and selfreported wheezing in school children, ${ }^{12}$ between proximity to major roads and prevalence of respiratory symptoms in children and adults, ${ }^{3-7}$ and between modelled estimates of air pollution from traffic and respiratory symptoms. ${ }^{8} 9$ An excess of hospital admissions or symptom reporting near roads, if reflecting a causal association, could either be the result of exacerbations among susceptible individuals or an increase in the prevalence of the condition.
In the UK, whereas a study in Birmingham showed a positive association between road traffic and hospital admission with asthma in children, ${ }^{10}$ Livingstone $e t$ a ${ }^{11}$ found no association of asthma diagnosis and treatment with proximity to major roads in London, and Waldron et $a l^{12}$ found a lower prevalence of self-reported wheeze in children living in electoral wards traversed by motorways. In 1995 a report by the Committee on the Health Effects of Outdoor Air Pollution ${ }^{13}$ concluded that available evidence does not "support a causative role for (non-biological) outdoor pollution" in the initiation of asthma, but recommended further analyses of "health service utilization in urban areas ... in relation to local traffic density ....". We report here such a study among children living in north west London which examines whether the risk of hospital admission for asthma is higher in those children living near major sources of road traffic emissions.

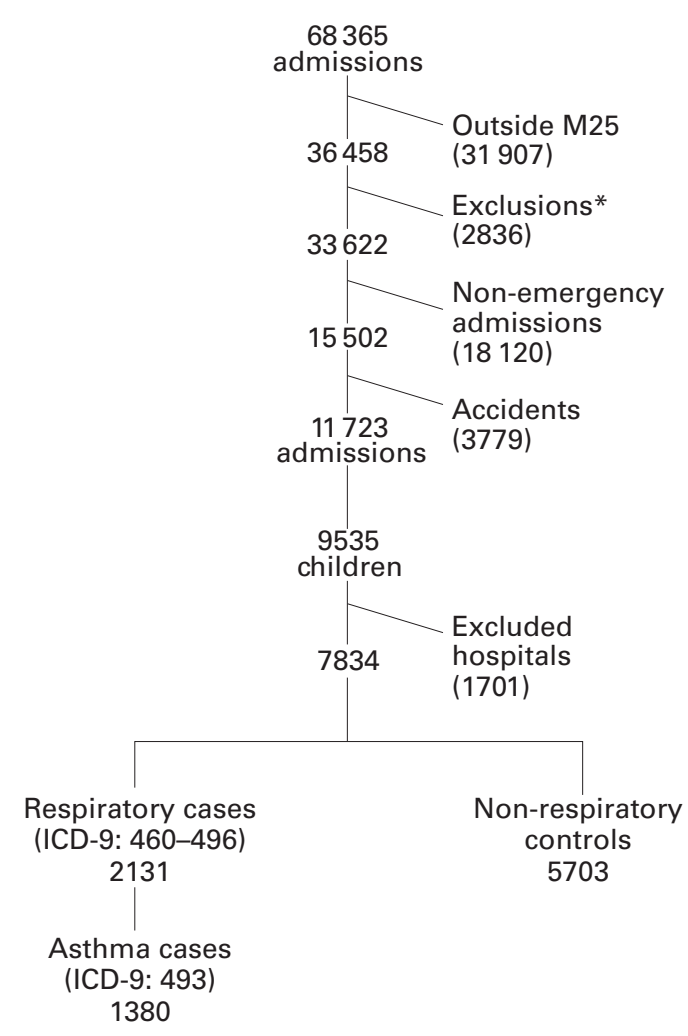

Figure 1 Identification of study population among hospital admissions in North Thames (West) health region (numbers of exclusions in parentheses). ${ }^{\star} A$ dmission for which the primary diagnosis was missing/invalid, age was inconsistent with dates, or first episode of current spell ended before study period. 


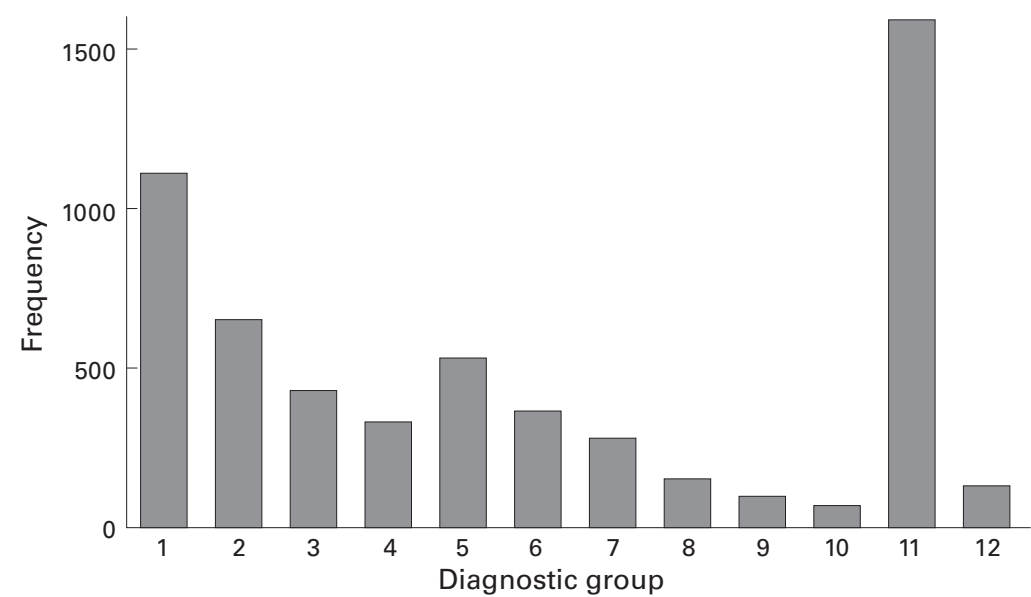

Figure 2 Primary diagnosis at first admission of control group: $1=$ digestive system disorder; 2 = infection; $3=$ musculoskeletal disorder $; 4=$ nervous system disorder $; 5=$ genitourinary disorder; $6=$ disorder of the blood forming organs; $7=$ disorder of the skin and subcutaneous tissue; $8=$ endocrine or nutritional disorder; $9=$ mental disorder; $10=$ neoplasm; 11 = ill defined symptoms and signs; $12=$ other.

\section{Methods}

This was a hospital based case-control study using routine postcoded regional Hospital Episode Statistics for children aged 5-14 years living in the North Thames (West) health region within the boundary of London's orbital M25 motorway. It was carried out for two years, April 1992 to March 1994. The Hospital Episode Statistics for England allocate each admission to the postcode of residence regardless of where that admission occurred nationally. The co-ordinates of the place of residence were determined from the centroid of the residential postcode $( \pm 10 \mathrm{~m})$ using the Ordnance Survey's Address Point. Separate admissions within the same individual were linked by matching date of birth, sex, and postcode. Analyses were also done for all admissionsthat is, including individuals admitted more than once during the study period. Two case groups, asthma (9th revision of International Classification of Diseases (ICD-9) 493) and respiratory illness (ICD-9 460-496), and controls were identified among emergency admissions using primary diagnosis for the first con-
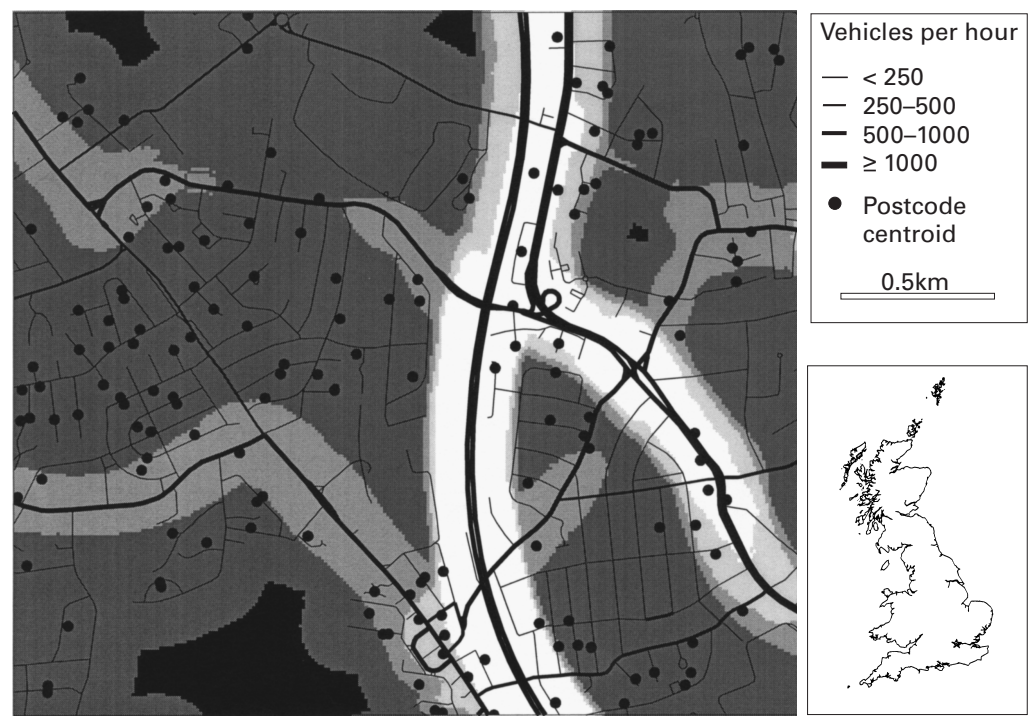

Figure 3 Exposure classification of postcode locations: traffic volumes were computed along road segments within $150 \mathrm{~m}$ of each point $(10 \times 10$ pixels $)$ giving the grey scale ranging from zero (black) to $>50000$ vehicle-metres/hour (white). (C) Crown \& Ordnance Survey. sultant episode of each admission (fig 1). Each case required at least one admission during the study period with a primary diagnosis of asthma or respiratory illness. Controls comprised all other children with an emergency admission during the study period (but not for respiratory illness) with the exclusion of admissions for accidental injuries and poisoning (ICD-9 800-999), the latter being excluded because of possible association between road accidents and residence close to a main road. Cases and controls from hospitals admitting five or fewer cases of asthma were excluded. The primary diagnosis at first admission for the control group is shown in fig 2 .

ROADS AND TRAFFIC VOLUMES

Data giving location of the centre lines of all roads within the study area $( \pm 1 \mathrm{~m})$ were obtained from the Ordnance Survey. Traffic data were derived from the London Research Centre's road traffic model for London, which comprises a set of links between road junctions with modelled peak hour flows (vehicles/hour) along interjunctional segments of all major through roads. ${ }^{14}$

Linking of the traffic model to Ordnance Survey data was carried out using a Geographical Information System. Once the links were created, all main roads (motorways, primary roads, $A$ roads, $B$ roads) and, in central London, also many minor roads were assigned estimated traffic volumes. For residential streets, which generally have low traffic volumes, the Department of Transport 1991 traffic report was used to assign them an average peak hour traffic flow. One of three different averages was applied depending on whether the street was located in outer, inner, or central London.

Measures of exposure to traffic were: (1) simple Euclidean distance to nearest main road; (2) distance to nearest road with a modelled peak hour traffic volume exceeding 1000 vehicles/hour; (3) computed traffic volume (vehicle-metres/hour) along roads within a radius of $150 \mathrm{~m}$ of the postcode centroid. Derivation of the latter variable entailed a two stage process: (1) conversion of the road network model into a raster grid of $10 \mathrm{~m} \times$ $10 \mathrm{~m}$ squares, each with an estimated peak hour flow, and (2) for each case and control the $10 \mathrm{~m} \times 10 \mathrm{~m}$ cells were selected within the specified distances and the sum obtained of their individual traffic flow values (fig 3). Traffic volumes within the different radii were categorised into quartiles but with the cut off points rounded to the nearest convenient number.

\section{STATISTICAL METHODS}

The main prior hypothesis related to the risk of hospital admission within $150 \mathrm{~m}$ of a main road. Simple and multiple logistic regression was used to examine the association between hospital admission for asthma/respiratory illness and the various markers of traffic exposure. Analyses were carried out for boys and girls separately and combined, but only the 
Table 1 Characteristics of study population

\begin{tabular}{|c|c|c|c|}
\hline & $\begin{array}{l}\text { Asthma cases } \\
(n=1380)\end{array}$ & $\begin{array}{l}\text { Respiratory cases } \\
(n=2131)\end{array}$ & $\begin{array}{l}\text { Controls } \\
(n=5703)\end{array}$ \\
\hline Mean (SD) age (years) & $8.4(2.8)$ & $8.4(2.9)$ & $9.5(2.9)$ \\
\hline Percent male & $63.3 \%$ & $60.4 \%$ & $55.9 \%$ \\
\hline Median Carstairs deprivation score (IQ range) & $0.25(-1.64$ to 2.29$)$ & $0.19(-1.66$ to 2.16$)$ & $0.03(-1.84$ to 1.95$)$ \\
\hline \multicolumn{4}{|l|}{ Distance in metres from major road (\%) } \\
\hline $0-74$ & $16.6 \%$ & $16.9 \%$ & $16.5 \%$ \\
\hline $75-149$ & $21.2 \%$ & $22.9 \%$ & $22.8 \%$ \\
\hline $150-299$ & $28.5 \%$ & $26.9 \%$ & $27.2 \%$ \\
\hline $300+$ & $33.7 \%$ & $33.3 \%$ & $33.5 \%$ \\
\hline Median distance from main road (IQ range) & $201.8(105.1$ to 370.7$)$ & $195.9(100.1$ to 373.9$)$ & $196.2(102.6$ to 378.5$)$ \\
\hline \multicolumn{4}{|l|}{ Traffic volume within $150 \mathrm{~m}$ (vehicle-metres/h) } \\
\hline$<1500$ & $28.7 \%$ & $28.8 \%$ & $27.5 \%$ \\
\hline $1500-14999$ & $25.7 \%$ & $24.0 \%$ & $23.4 \%$ \\
\hline $15000-49999$ & $24.3 \%$ & $24.7 \%$ & $27.3 \%$ \\
\hline $50000+$ & $21.2 \%$ & $22.5 \%$ & $21.8 \%$ \\
\hline
\end{tabular}

results of the combined analyses are tabulated. Odds ratios are given together with 95\% confidence intervals. The logistic model assumes that risk falls exponentially with distance; further analysis using the non-linear binary regression model of Diggle and Rowlingson ${ }^{15}$ was done which, though similar to the logistic model, has the advantage that risk at distance is allowed to converge to background. For both methods, tests for improvements in model fit were based on comparisons of likelihood ratios. We estimated that the study had approximately $90 \%$ power to detect a difference of $20 \%$ in the risk of asthma admission between children living within $150 \mathrm{~m}$ of a main road and those living further away.

Adjustment for hospital in the regression analyses allowed for possible variation between hospitals in completeness of data and diagnostic coding. To control for possible socioeconomic confounding, each child was assigned a Carstairs deprivation score for the census enumeration district in which he or she lived. ${ }^{16}$ This is based on four variables from the 1991 census small area statistics: overcrowding, social class, unemployment, and access to a car. Twenty one children lived in enumeration districts with insufficient population to compute a Carstairs score and were excluded from analysis where socioeconomic adjustment was required.

Table 2 Numbers (\%) of children with at least one hospital admission for asthma by distance of residence from main road

\begin{tabular}{lll}
\hline & Cases of asthma & Non-respiratory controls \\
\hline Living within $150 \mathrm{~m}$ of main road & $522(37.8 \%)$ & $2240(39.3 \%)$ \\
Living $>150$ m from main road & $858(62.2 \%)$ & $3463(60.7 \%)$ \\
\hline
\end{tabular}

Odds ratios $\dagger(95 \%$ confidence intervals $)$ : unadjusted $=0.94(0.83$ to 1.06$), p=0.32$; adjusted $\neq=$ $0.93(0.82$ to 1.06$), \mathrm{p}=0.27$.

tOdds of hospital admission with asthma in children living within $150 \mathrm{~m}$ of main road compared with odds for those living further away.

$\ddagger$ Adjusted for age, sex, hospital, and deprivation.

Table 3 Odds ratios with 95\% confidence intervals for hospital admission for asthma by traffic volume within $150 \mathrm{~m}$ of place of residence

\begin{tabular}{lll}
\hline Volume within $150 \mathrm{~m}$ & Unadjusted & $\begin{array}{l}\text { Adjusted for age, sex, hospital } \\
\text { and deprivation }\end{array}$ \\
\hline$<1500$ & 1.0 & 1.0 \\
$1500-14999$ & $1.06(0.90$ to 1.24$)$ & $1.03(0.87$ to 1.22$)$ \\
$15000-49999$ & $0.86(0.73$ to 1.00$)$ & $0.80(0.68$ to 0.95$)$ \\
$50000+$ & $0.93(0.79$ to 1.11$)$ & $0.88(0.74$ to 1.06$)$ \\
Statistical tests: & & \\
$\quad \begin{array}{l}\text { Heterogeneity (3 df) } \\
\text { Trend (1 df) }\end{array}$ & $\chi^{2}=6.83 ; \mathrm{p}=0.08$ & $\chi^{2}=10.4 ; \mathrm{p}=0.02$ \\
\hline
\end{tabular}

\section{Results}

After exclusions, data were available on 1380 cases of asthma, 2131 cases of respiratory illnesses (which includes the asthma cases), and 5703 non-respiratory controls (fig 1 and table 1). Eighty four percent of the children had been admitted to hospital only once during the study period. Asthma and respiratory cases tended to be younger than the controls with a higher proportion of boys. Median deprivation scores, distributions of distance from a main road, and estimated traffic volumes within $150 \mathrm{~m}$ were all similar for cases and controls (table 1).

There was no association between residence within $150 \mathrm{~m}$ of a main road and risk of hospital admission for asthma (table 2). The corresponding odds ratios for respiratory admission were 1.02 (95\% CI 0.92 to 1.13 ) for the unadjusted analysis and 1.02 (95\% CI 0.92 to 1.14) after adjustment for age, sex, admitting hospital, and deprivation. There was no significant interaction between the effect of hospital and distance from roads. Similar results were obtained for distance to a road with a peak hour traffic volume exceeding 1000 vehicles, and when distance was treated as a continuous rather than a dichotomous variable (data not tabulated). For example, in the fully adjusted analysis, the odds ratio for asthma admission for each $1000 \mathrm{~m}$ nearer to a main road was 0.96 (95\% CI 0.75 to 1.23$)$. Tests based on the method of Diggle and Rowlingson gave concordant results $(p=0.9$ for the effect of distance from a main road on risk of asthma admission in the fully adjusted model).

Odds ratios for hospital admission with asthma by traffic volume within $150 \mathrm{~m}$ of the home (table 3) suggested some heterogeneity of risk across exposure categories in the age, sex, hospital, and deprivation adjusted model, and there was a borderline significant trend ( $p$ $=0.06$ ) of decreasing risk with increasing traffic volumes - that is, in a direction opposite to that hypothesised. Results for hospital admission with respiratory illness (not tabulated) show a similar, but not statistically significant, pattern. Analyses based on all admissions - that is, allowing more than one admission per childyielded results very similar to those of table 3, with evidence of a decline in risk of hospital admission with asthma at postcodes of higher traffic volume $(\mathrm{p}=0.02$ for trend before and 
after adjustment for age, sex, hospital, and socioeconomic deprivation).

\section{Discussion}

This study of 7834 children from north west London showed no association between risk of hospital admission with asthma or respiratory illness and proxies for traffic related pollution at the place of residence. This accords with results of a recent study of general practitioner diagnosis of, and treatment for, asthma in relation to proximity of residence to busy roads in east London, but contrasts with the findings of other studies. ${ }^{1-10}$

In common with all but two of these studies, ${ }^{89}$ we used a proxy for exposure to road traffic based on proximity to a major road or estimated traffic volumes rather than modelled estimates of ambient air pollution. Such studies take no account of vehicle type, periods of acceleration and deceleration, and vehicle speed, all of which affect emission levels. Furthermore, ambient pollution concentrations depend on atmospheric chemistry, dispersion processes and meteorological conditions, as well as emissions. Whereas it seems probable that proximity to a main road is a reasonable surrogate for the outdoor concentrations of most traffic related pollutants, for others such as ozone it will be a poor marker because photochemical oxidation leads to reduced levels near traffic sources. ${ }^{17}$

In none of the studies to date, including our own, have data on indoor air pollution or integrated personal exposures been considered. Categorisation of individuals based on place of residence clearly makes the unrealistic assumptions that (1) children are not exposed in the home to major indoor sources and (2) they do not move about within the urban environment. In comparison with the few other reported studies, we have attempted as far as possible to refine the measures of exposure based on distance methods by including a traffic volume measure for each individual based on Geographical Information System techniques. Our methods are still likely to have led to appreciable, but unquantified, misclassification of exposure for individuals. Misclassification is also possible in the categorisation of cases and controls, although a recent study of hospital admissions in the North Thames (West) health region $^{18}$ reported $88 \%$ agreement between local and external coders in the three digit coding of primary diagnosis of asthma. Such misclassifications will lead to underestimates of any true association between asthma admissions and road traffic.

A number of potentially important confounding factors including parental smoking were not considered in the analyses as they are unavailable in the routine data. Nonetheless, control for such confounding was achieved to some extent by adjusting for Carstairs deprivation index which has been shown to predict smoking patterns among individuals in North West Thames. ${ }^{19}$ It is unclear to what extent confounding may have contributed to the positive associations reported in other studies.
Two of the positive studies related to pre-school age children, in whom place of residence is more likely to reflect true exposure to traffic related pollutants as, in this age group, children spend more of their time close to home. These very young children may be more susceptible to the effects of air pollution than older children, although the spectrum of disease is different and will include a number of respiratory conditions other than true asthma.

There was a suggestion of an inverse association between asthma and traffic density. While this may be a chance finding, there is a possibility of selection bias. Families with asthmatic children may choose to live away from major roads because of concern for their children's health.

Although there may be reasons why we failed to find an association between road traffic and respiratory health if one exists, this result is not exceptional. ${ }^{20}$ Recent evidence from a panel study in Holland ${ }^{21}$ found that only the subgroup of children with bronchial hyperresponsiveness and high serum concentrations of IgE appeared susceptible to air pollution, which suggests an interaction between pollution and allergic response. Further work is needed to disentangle this interaction and the underlying mechanisms, but the balance of evidence remains that outdoor air pollution has at most a modest effect on asthmatic symptoms.

In conclusion, based on routine data sources and with acknowledged limitations in exposure classification, the study found no evidence of an association between hospital admissions for asthma and respiratory illness in school aged children in relation to road traffic. Improved markers of exposure to traffic related pollutants for use in epidemiological studies are required. ${ }^{22}$

This study was supported by a British Lung Foundation/3M Health Care Research Fellowship grant. The authors are grateful to Ordnance Survey for supplying high resolution road topography data for the London area (OSCAR Asset Manager), and to David Hutchinson of the London Research Centre for providing the road traffic model for London. Work in this repor is copyright Crown and Ordnance Survey.

1 Wjst M, Reitmar M, Dold S, et al. Road traffic and adverse effects on respiratory health in children. $B M \mathcal{F}$ 1993;307:596-600

2 Weiland SK, Nundt KA, Rueckmann A, et al. Self-reported wheezing and allergic rhinitis in children and traffic-density on street of residence. Ann Epidemiol 1994;4:79-83.

3 Oosterlee A, Drijver M, Lebret E, et al. Chronic respiratory symptoms in children and adults living along streets with high traffic density. Occup Environ Med 1996;53:241-7.

4 Van Vliet P, Knape M, De Hartog J, et al. Motor vehicle exhaust and chronic respiratory symptoms in children living near freeways. Environ Res 1997;74:122-32.

5 Nitta H, Sato T, Nakai S, et al. Respiratory health Nitta H, Sato T, Nakai S, et al. Respiratory health
associated with exposure to automobile exhaust. I. Results of cross-sectional studies. Arch Environ Health 1993;48: of cross-8.

6 Murakami M, Ono M, Tamura K. Health problems of residents along heavy-traffic roads. F Human Ergol 1990;19: $101-6$

7 Nikai S, Crest J, Nitta H, et al. Respiratory health associated with exposure to automobile exhaust. III. Results of a cross-sectional study in 1987, and repeated pulmonary function tests from 1987 to 1990. Arch Environ Health 1999;54:26-32.

8 Norsk Institut fur Luftforskning (NILU). The health effects of traffic pollution as measured in the Valerenga area of Oslo. traffic pollution as measured in the Valerenga area of Oslo.
Summary report. Lillestrom: Norsk Institut fur Luftforskning, 1991.

9 Pershagen G, Rylander E, Norberg S, et al. Air pollution involving nitrogen dioxide exposure and wheezing bronchitis in children. Int $\mathcal{F}$ Epidemiol 1995;24:1147-53. 
10 Edwards J, Walters S, Griffiths RK. Hospital admissions for asthma in preschool children: relationship to major roads in Birmingham, United Kingdom. Arch Environ Health 1994; 49:223-7.

11 Livingstone AE, Shaddick G, Grundy C, et al. Do people living near inner city main roads have more asthma needin treatment? A case control study using routine general practice data. BMf 1996;312:676-7.

12 Waldron G, Pottle B, Dod J. Asthma and motorways: one district's experience. F Publ Health Med 1995;17:85-9.

13 Committee on the Medical Effects of Air Pollutants. Asthma and outdoor air pollution. London: HMSO, 1995.

14 London Research Centre. London Energy Study. Road Transport Methodology. London, 1993.

15 Diggle P, Rowlingson B. A conditional approach to point process modelling of elevated risk. $f R$ Statist Soc $A$ process modelling

16 Carstairs V, Morris R. Deprivation: explaining differences in mortality between Scotland and England. BMF 1989;299: $886-9$
17 Advisory Group on the Medical Aspects of Air Pollution Episodes. First report. Ozone. Department of Health, London: HMSO, 1991

18 Dixon J, Sanderson C, Elliott P, et al. Assessment of the reproducibility of clinical coding in routinely collected hospital activity data: a study in two hospitals. I Publ Health Med 1998;20:63-9.

19 Kleinschmidt I, Hills M, Elliott P. Smoking behaviour can be predicted by neighbourhood deprivation measures. $f$ Epidemiol Community Health 1995;49:S72-7.

20 Burney P. Air pollution and asthma: the dog that doesn't always bark. Lancet 1999;353:859-60.

21 Boezen HM, van der Zee SC, Postma DS, et al. Effects of ambient air pollution on upper respiratory symptoms and peak expiratory flow in children. Lancet 1999;353: 874-8.

22 Elliott P, Briggs D, Lebret E, et al. Small area variations in air quality and health (the SAVIAH study): design and methods. Epidemiology 1995;6:S32. 